\title{
Pulmonary hypertension in Nigerian adults with sickle cell anemia
}

This article was published in the following Dove Press journal:

Vascular Health and Risk Management

8 May 2017

Number of times this article has been viewed

\section{Valentine N Amadi' \\ Michael O Balogun ${ }^{2}$ \\ Norah O Akinola ${ }^{3}$ \\ Rasaaq A Adebayo ${ }^{2}$ \\ Anthony O Akintomide ${ }^{2}$}

'Department of Internal Medicine, Federal Medical Centre, Asaba, Delta State, ${ }^{2}$ Cardiac Care Unit, Department of Medicine, ${ }^{3}$ Department of Haematology and Blood Transfusion, Obafemi Awolowo University Teaching Hospitals Complex, Ile-Ife, Osun State, Nigeria
Correspondence: Valentine N Amadi Department of Internal Medicine, Federal Medical Centre, I Anwai Road, PMB 1033, Asaba, Delta State, Nigeria

Tel +2348062625318

Email mekuslala@yahoo.com
Background: Sickle cell anemia (SCA) is the commonest hemoglobinopathy and is associated with high morbidity and mortality. Pulmonary hypertension $(\mathrm{PH})$ is reported to play a significant role in this regard. There is very limited literature on PH in SCA in Nigeria.

Objectives: The objectives of this study were to determine the prevalence of Doppler-derived $\mathrm{PH}$ in SCA, assess its influence on exercise capacity, and determine the correlates and predictors of measures of estimated pulmonary pressure.

Methods: A total of 92 SCA subjects had echocardiography and 6-minute self-paced walking exercise. PH was diagnosed by Doppler echocardiography on finding a tricuspid regurgitant velocity (TRV) of $\geq 2.5 \mathrm{~m} / \mathrm{s}$. The pulmonary flow profile was also assessed to estimate mean pulmonary arterial pressure (MPAP).

Results: Doppler-derived PH was detected in $23.9 \%$ of adults with SCA. The 6-minute walking distance (6MWD) was significantly lower in SCA adults with PH than in those without PH (380.33 $\pm 63.17 \mathrm{~m}$ vs $474.28 \pm 76.74 \mathrm{~m} ; p=0.014)$. TRV and estimated MPAP had a significant inverse correlation with the 6MWD ( $r=-0.442 ; p<0.001$ and $r=-0.571 ; p<0.001$, respectively).

Conclusion: $\mathrm{PH}$ as derived by Doppler is common in Nigerian adults with SCA and has a significantly negative influence on exercise capacity. Screening for PH should be encouraged to optimize management and thus improve their quality of life and life expectancy.

Keywords: pulmonary hypertension, Nigerian adults, sickle cell anemia, doppler-derived

\section{Introduction}

Sickle cell anemia (SCA), the commonest hemoglobinopathy worldwide, is associated with reduced life expectancy and early death, and pulmonary hypertension $(\mathrm{PH})$ is reported to play a significant role in this regard. ${ }^{1,2} \mathrm{PH}$ is increasingly recognized in patients with sickle cell disease (SCD), with a prevalence reported as high as $30 \%$ in echocardiography-based studies. ${ }^{2,3} \mathrm{PH}$ is defined by a mean pulmonary artery pressure $>25 \mathrm{mmHg}$ at rest, measured during right heart catheterization. ${ }^{4,5}$ There is still insufficient evidence to add exercise criterion to this definition. ${ }^{4}$

In $\mathrm{PH}$, the structural and functional exchanges that constitute remodeling of the vascular walls, principally of the pulmonary artery segment, significantly reduce compliance in the pulmonary circulation. This creates an environment for elevation of pressure values and pulmonary vascular resistance in response to increased cardiac output, such as that occurring on exertion, during controlled exercise or even at rest, being proportional to the degree of remodeling and to the reduction in the functional reserve of the pulmonary circulation. ${ }^{6}$ 
Classification of $\mathrm{PH}$ has evolved over time from a simple classification into "primary and secondary" to that adopted by the World Health Organization (WHO) in Evans, France (1998), where it was classified into four categories, based on similarities in pathophysiology, clinical presentation, and therapeutic options, and to that adopted by the WHO in Venice, Italy (2003), in which a fifth multifactorial category was included.

The etiology of PH in SCA is multifactorial. A close look at the four categories reveals the following observation:

1. Chronic intravascular hemolysis may be associated with endothelial dysfunction, including reduced nitric oxide bioavailability, coagulopathy, and prooxidant and proinflammatory stress, which may contribute to the development of proliferative changes in the pulmonary vasculature, much like those observed in patients with idiopathic pulmonary arterial hypertension (PAH). ${ }^{7}$ Cell-free plasma hemoglobin, heme, and arginase-1 released during hemolysis have recently been referred to as erythrocyte damage-associated molecular pattern molecules (eDAMPs). ${ }^{8}$

2. Many patients with SCA have elevated left heart filling pressures as a result of a chronically elevated cardiac output or diastolic dysfunction and would therefore be classified as group 2 or those with pulmonary venous hypertension. ${ }^{9}$

3. Over the course of time, some patients with SCA develop parenchymal lung disease from recurrent acute chest syndrome, putting them at risk for PH (group 3). ${ }^{9}$

4. Finally, patients with SCA are at increased risk for the development of pulmonary thromboembolic disease and, potentially, chronic thromboembolic PH (group 4). ${ }^{9}$

In the recent fifth world symposium held in Nice, France, in 2013, PH due to SCD was categorized into the fifth subgroup, which takes into cognizance the multifactorial nature of its development. ${ }^{10-12}$

Definitive diagnosis of $\mathrm{PH}$ requires right heart catheterization; however, transthoracic Doppler echocardiography can aid in the assessment of $\mathrm{PH} .^{5,13}$ The use of tricuspid regurgitant velocity (TRV) alone does not equate to a clinical definition of $\mathrm{PH}$, but it does define mortality risk and identifies patients at higher risk of $\mathrm{PH} .^{2,3,14}$

In Nigeria, studies on PH in SCA are scarce. There is also little information on its relationship with exercise and other clinical and echocardiographic parameters in adult Nigerians with SCA.

This study therefore determined the prevalence of Doppler-derived $\mathrm{PH}$ in patients with SCA, evaluated its influence on exercise capacity, and determined the correlates and predictors of measures of pulmonary pressure in these patients seen at the Department of Haematology and Blood Transfusion and Cardiac Care Unit of Obafemi Awolowo University Teaching Hospitals Complex (OAUTHC), Ile-Ife, a tertiary hospital in Southwestern Nigeria. The findings from this study will add more information to the national and global databases.

\section{Methods}

A total of 92 homozygous hemoglobin S adults were consecutively recruited from the Haematology Clinic of the OAUTHC. Diagnosis of SCA (HbSS) had been confirmed previously by hemoglobin electrophoresis. The patients were recruited into the study within a 6-month period from January 2012 to June 2012. Patients aged $\geq 18$ years who were in steady state were included in the study. Steady state was defined as being crisis-free for at least 3 weeks since the last clinical event and remaining crisis-free for up to one week after the tests were conducted, as well as not having had a blood transfusion in the preceding 3 months. ${ }^{15}$ Patients with severe anemia, ie, hematocrit or packed cell volume (PCV) $<18 \%$, abnormal renal function, and coexisting heart diseases such as hypertensive heart disease, valvular heart disease, cardiomyopathies, and congenital heart disease, which could act as confounders, were excluded from the study. Data were obtained using a pro forma that included demographic data, relevant history, and physical examination. Baseline laboratory tests, including hematocrit and renal function test, were carried out to determine suitability for inclusion in the study.

Echocardiography was conducted using the Vivid 7 Pro (General Electric, Boston, MA, USA) model echocardiography machine and involved two-dimensional, M-mode, conventional Doppler (pulsed and continuous wave) and tissue Doppler studies to assess cardiac structure and function and to detect exclusion criteria such as coexisting heart diseases, as mentioned earlier.

The study was conducted using the $5 \mathrm{~S}$ transthoracic phased array sector probe for adults with transducer frequency of 2.2-5.0 MHz. Measurements were in accordance with the recommendations of the American Society of Echocardiography and involved taking an average of three consecutive cycles. ${ }^{16}$

Left ventricular wall and chamber dimensions, left atrial dimension, and cardiac output were measured using 2D-guided M-mode echocardiography with simultaneous electrocardiographic monitoring of the cardiac cycle. Echocardiographic assessment of PH was obtained using two methods:

1. Determination of peak TRV by continuous wave Doppler by placing the cursor along the tricuspid regurgitant jet in 
the apical four chamber view after obtaining a color Doppler display of tricuspid regurgitation jet across the valve.

2. Determination of the right ventricular acceleration time (AT) and the ratio of right ventricular acceleration time to right ventricular ejection time (AT/RVET) from the pulmonary ejection flow jet obtained by continuous wave Doppler with sample volume just proximal to the pulmonary valve in the parasternal short axis view. The acceleration time was taken as the time interval from the onset of right ventricular ejection to peak ejection velocity, while the ejection time was taken as the time interval from the onset to the end of ejection.

An assessment of $\mathrm{PH}$ was made on the following finding:

1. a peak TRV of $\geq 2.5 \mathrm{~m} / \mathrm{s}^{3}$ or

2. an AT $<100 \mathrm{~ms}$ with an AT/RVET ratio of $<0.30$.

The use of both a cutoff point of $100 \mathrm{~ms}$ and a ratio of AT/ RVET is due to the wide variation in cutoff points ranging from 80 to $100 \mathrm{~ms}$ in screening for $\mathrm{PH}$ reported by different studies. ${ }^{17,18}$ The aim of using this combination was to reduce the chances of over- or under inclusion if a single cutoff value of AT alone was used.

Mean pulmonary arterial pressure (MPAP) was estimated using the regression equation developed by Dabestani et al: ${ }^{18}$ MPAP $(\mathrm{mmHg})=90-(0.62 \times$ AT $)$.

The participants also underwent a 6-minute walking distance (6MWD) test. They were instructed not to participate in strenuous physical activity the day before exercise nor to ingest coffee, drugs, alcohol, or nicotine within 12 hours of exercise testing and to observe a pre-exercise rest period of 10 minutes. The test was performed indoors, along a long, flat, straight, enclosed corridor with a hard surface that is seldom used. The length of the corridor was $20 \mathrm{~m}$. The turnaround points were marked with a cone. A starting line was marked on the floor with a bright colored tape to denote the beginning and end of each $40 \mathrm{~m}$ lap. Volunteers were asked to walk to and fro on this smooth corridor as fast as possible to cover enough ground within 6 minutes. The $6 \mathrm{MWD}$ was determined at the end of the exercise.

Data were entered into SPSS version 17.0 computer software package (IBM Corporation, Chicago, IL, USA). Results were presented in tables and graphs. Appropriate descriptive and inferential statistical tests were used to determine relationships between variables. Statistical significance was defined as a $p$ value $<0.05$.

This study complied with the Declaration of Helsinki. Ethical clearance was obtained from the ethics and research committee of the OAUTHC, Ile-Ife, Nigeria, and informed consent was obtained from the study participants.

\section{Results}

A total of 92 SCA patients participated in the study, comprising of 42 males and 50 females. The clinical and demographic parameters are listed in Table 1. The age ranged from 18 to 41 years with a mean age of 25.4 years. The $\mathrm{PCV}$ ranged from $20 \%$ to $35 \%$ with a mean PCV of $26.8 \%$. Other parameters are as shown in the table.

\section{Prevalence of Doppler-derived $\mathrm{PH}$ among the study population}

The criteria using TRV of $2.5 \mathrm{~m} / \mathrm{s}$ as a cutoff point yielded a prevalence of $23.9 \%$ (22 out of 92 ), while that using the pulmonary flow jet increased the yield to $38.0 \%$ (35 out of 92). All patients who met the first criterion met the second, but the corollary was not true. The sex distribution of $\mathrm{PH}$ among patients with SCA showed no statistically significant difference. A total of 15 (35.7\%) of the 42 males had $\mathrm{PH}$, while $20(40 \%)$ of the 50 females had PH $\left(\chi^{2}=0.178 ; p=0.673\right)$.

Table 2 shows the relationship between Doppler-derived $\mathrm{PH}$ and the clinical parameters of the patients. Patients with SCA with $\mathrm{PH}$ were older $(28.6 \pm 5.78$ years vs $23.4 \pm$ 3.41 years; $p<0.001)$, had lower PCV $(25.6 \% \pm 2.92 \%$ vs $27.5 \% \pm 2.35 \% ; p=0.001)$, and had lower 6 -minute walk

Table I Clinical and demographic parameters of the study patients

\begin{tabular}{llll}
\hline Parameter & Minimum & Maximum & Mean \pm SD \\
\hline Age (years) & 18.0 & 41.0 & $25.4 \pm 5.14$ \\
Weight $(\mathrm{kg})$ & 29.0 & 74.0 & $51.0 \pm 7.7$ \\
Height $(\mathrm{m})$ & 1.30 & 1.92 & $1.64 \pm 0.08$ \\
BMI $\left(\mathrm{kg} / \mathrm{m}^{2}\right)$ & 14.2 & 24.98 & $19.0 \pm 1.9$ \\
BSA $\left(\mathrm{m}^{2}\right)$ & 1.02 & 1.99 & $1.52 \pm 0.14$ \\
PCV $(\%)$ & 20.0 & 35.0 & $26.7 \pm 2.72$ \\
Hb Conc $(\mathrm{g} / \mathrm{dL})$ & 6.67 & 11.7 & $8.91 \pm 0.91$ \\
SBP $(\mathrm{mmHg})$ & 80.0 & 130.0 & $106.4 \pm 10.2$ \\
DBP $(\mathrm{mmHg})$ & 50.0 & 86.0 & $64.5 \pm 8.9$ \\
\hline
\end{tabular}

Abbreviations: BMI, body mass index; BSA, body surface area; PCV, packed cell volume; Hb Conc, hemoglobin concentration; SBP, systolic blood pressure; DBP, diastolic blood pressure.

Table 2 Relationship between $\mathrm{PH}$ and clinical parameters

\begin{tabular}{llll}
\hline Parameter & PH & No PH & P value \\
\hline Age (years) & $28.6 \pm 5.8$ & $23.4 \pm 3.4$ & $<0.00 I^{*}$ \\
PCV (\%) & $25.6 \pm 2.9$ & $27.5 \pm 2.4$ & $0.00 I^{*}$ \\
HR (beats $/ \mathrm{min})$ & $84.0 \pm 8.2$ & $83.3 \pm 3.7$ & 0.616 \\
SBP $(\mathrm{mmHg})$ & $107.5 \pm 12.1$ & $105.5 \pm 8.9$ & 0.264 \\
DBP $(\mathrm{mmHg})$ & $64.5 \pm 10.2$ & $64.5 \pm 8.2$ & 0.987 \\
BMI $\left(\mathrm{kg} / \mathrm{m}^{2}\right)$ & $19.1 \pm 2.6$ & $18.9 \pm 1.4$ & 0.810 \\
BSA $\left(\mathrm{m}^{2}\right)$ & $1.50 \pm 0.15$ & $1.53 \pm 0.14$ & 0.482 \\
6MWD $(\mathrm{m})$ & $380.3 \pm 63.2$ & $474.3 \pm 76.7$ & $0.014^{*}$ \\
\hline
\end{tabular}

Note: *Statistically significant.

Abbreviations: $\mathrm{PH}$, pulmonary hypertension; $\mathrm{PCV}$, packed cell volume; $\mathrm{HR}$, heart rate; SBP, systolic blood pressure; DBP, diastolic blood pressure; BMI, body mass index; BSA, body surface area; 6MWD, 6-minute walk distance. 
distance $(380.3 \pm 63.2 \mathrm{~m}$ vs $474.3 \pm 76.7 \mathrm{~m} ; p=0.014)$ than those without PH. Other clinical parameters were not significantly different between the two groups $(p>0.05)$.

Table 3 shows the strength of correlation between the echo parameters of PH and 6MWD. Parameters derived from both tricuspid regurgitation and pulmonary flow jets all correlated significantly with the 6MWD. TRV had a negative correlation with 6MWD $(r=-0.442 ; p<0.001)$. The AT and, by extension, the MPAP had the strongest correlation $(r=0.571$ and $r=-0.571$, respectively; $p<0.001$ ).

Table 4A and B shows the relationship between $\mathrm{PH}$ and echocardiographic structural and functional parameters, respectively. As shown, SCA subjects with PH had larger left atrial dimensions and index, left ventricular internal diastolic dimension index, end-diastolic volume index, endsystolic volume index, right ventricular wall thickness, right ventricular internal diameter and index, and left ventricular mass index than those without PH $(p<0.05)$. With regard to left ventricular systolic function, subjects with $\mathrm{PH}$ had significantly lower ejection fraction $(p=0.004)$, fractional shortening $(p=0.009)$, and tissue Doppler systolic velocity $(p<0.001)$ than those without PH. In terms of left ventricular diastolic function, those with $\mathrm{PH}$ had significantly lower early mitral annular tissue diastolic velocity $\left(e^{\prime}\right)$ but higher $E / e^{\prime}$ ratio $(p<0.001)$ than those without $\mathrm{PH}$.

Table 5A lists the statistically significant correlates of TRV. They include age $(r=0.352)$, hematocrit $(r=-0.326)$, tissue Doppler systolic velocity $(r=-0.462)$, left ventricular internal diastolic dimension index $(r=0.434)$, left atrial dimension index $(r=0.290)$, left ventricular ejection fraction $(r=-0.339)$, early mitral annular tissue diastolic velocity $(r$ $=-0.279)$, and $E / e^{\prime}$ ratio $(r=0.270)$. Table $5 \mathrm{~B}$ lists the independent parameters linked to tricuspid regurgitation velocity, which include left atrial dimension index, tissue Doppler systolic velocity, and hematocrit. Figure 1 shows a scatter plot depicting the correlation between maximum TRV and 6MWD. The higher the maximum TRV, the lower the 6MWD.

Table 3 Correlation strength between parameters of $\mathrm{PH}$ and 6MWD

\begin{tabular}{lll}
\hline Parameter & Pearson correlation coefficient & $\boldsymbol{p}$ value \\
\hline TRV $_{\text {max }}(\mathrm{m} / \mathrm{s})$ & -0.442 & $<0.00 I^{*}$ \\
AT $(\mathrm{ms})$ & 0.571 & $<0.00 I^{*}$ \\
AT/RVET & 0.557 & $<0.00 I^{*}$ \\
MPAP $(\mathrm{mmHg})$ & $-0.57 \mathrm{I}$ & $<0.00 I^{*}$ \\
\hline
\end{tabular}

Note: *Statistically significant.

Abbreviations: $\mathrm{PH}$, pulmonary hypertension; 6MWD, 6-minute walk distance; AT, right ventricular acceleration time; AT/RVET, ratio of right ventricular acceleration time to right ventricular ejection time; MPAP, mean pulmonary arterial pressure; $T R V_{\text {max }}$, maximum tricuspid regurgitant velocity.
Table 4 Relationship between $\mathrm{PH}$ and echocardiographic (A) structural parameters and (B) functional parameters

\begin{tabular}{|c|c|c|c|}
\hline \multicolumn{4}{|l|}{ A } \\
\hline Parameter & PH present & PH absent & $p$ value \\
\hline LAD (cm) & $3.9 \pm 0.4$ & $3.6 \pm 0.4$ & $<0.00 I^{*}$ \\
\hline LADi $\left(\mathrm{cm} / \mathrm{m}^{2}\right)$ & $2.63 \pm 0.35$ & $2.4 \pm 0.2$ & $<0.00 I^{*}$ \\
\hline LVIDD (cm) & $5.1 \pm 0.6$ & $4.9 \pm 0.5$ & 0.080 \\
\hline LVIDDi $\left(\mathrm{cm} / \mathrm{m}^{2}\right)$ & $3.4 \pm 0.5$ & $3.21 \pm 0.3$ & $0.010 *$ \\
\hline $\mathrm{EDV}(\mathrm{mL})$ & $125.7 \pm 36.0$ & $\mid I 4.1 \pm 28.6$ & 0.080 \\
\hline EDVi $\left(\mathrm{mL} / \mathrm{m}^{2}\right)$ & $83.8 \pm 23.5$ & $74.2 \pm 15.1$ & $0.019 *$ \\
\hline ESV (mL) & $42.8 \pm 17.8$ & $34.0 \pm 11.3$ & 0.080 \\
\hline ESVi $\left(m L / m^{2}\right)$ & $28.3 \pm 11.8$ & $22.0 \pm 6.01$ & $0.001 *$ \\
\hline IVST (cm) & $0.90 \pm 0.13$ & $0.89 \pm 0.14$ & 0.937 \\
\hline LVPWT (cm) & $1.08 \pm 0.19$ & $1.01 \pm 0.17$ & 0.090 \\
\hline RVWT (cm) & $0.48 \pm 0.07$ & $0.38 \pm 0.06$ & $<0.00 I^{*}$ \\
\hline RVIDD (cm) & $1.9 \pm 0.5$ & $1.6 \pm 0.3$ & $0.004^{*}$ \\
\hline RVIDDi $\left(\mathrm{cm} / \mathrm{m}^{2}\right)$ & $1.3 \pm 0.3$ & $\mathrm{I} . \mathrm{I} \pm 0.2$ & $0.002 *$ \\
\hline LVMi & $124.9 \pm 31.4$ & $109.6 \pm 27.5$ & $0.016 *$ \\
\hline RWT & $0.39 \pm 0.06$ & $0.39 \pm 0.05$ & 0.985 \\
\hline \multicolumn{4}{|l|}{ B } \\
\hline Parameter & PH present & PH absent & $p$ value \\
\hline LVEF (\%) & $66.7 \pm 7.3$ & $70.4 \pm 4.6$ & $0.004 *$ \\
\hline LVFS (\%) & $37.4 \pm 5.2$ & $40.0 \pm 3.9$ & $0.009 *$ \\
\hline $\mathrm{SV}(\mathrm{mL})$ & $83.0 \pm 23.7$ & $80.0 \pm 19.3$ & 0.523 \\
\hline $\mathrm{SI}\left(\mathrm{mL} / \mathrm{m}^{2}\right)$ & $55.5 \pm 15.8$ & $52.2 \pm 10.7$ & 0.235 \\
\hline $\mathrm{CO}(\mathrm{L} / \mathrm{min})$ & $6.9 \pm 1.9$ & $6.7 \pm 1.6$ & 0.467 \\
\hline $\mathrm{Cl}\left(\mathrm{L} / \mathrm{min} / \mathrm{m}^{2}\right)$ & $4.6 \pm 1.3$ & $4.3 \pm 0.9$ & 0.205 \\
\hline$E^{0}(\mathrm{~m} / \mathrm{s})$ & $I .1 \pm 0.2$ & $1.02 \pm 0.1$ & 0.145 \\
\hline$E / A$ & $1.5 \pm 0.3$ & $1.6 \pm 0.2$ & 0.201 \\
\hline $\mathrm{TDe}^{\prime}(\mathrm{cm} / \mathrm{s})$ & $1 I .1 \pm 2.0$ & $12.6 \pm 1.3$ & $<0.00 I^{*}$ \\
\hline $\mathrm{TDs}^{\prime}(\mathrm{cm} / \mathrm{s})$ & $7.3 \pm 1.2$ & $8.4 \pm 1.0$ & $<0.00 I^{*}$ \\
\hline$E / \mathrm{e}^{\prime}$ & $9.8 \pm 2.7$ & $8.1 \pm 1.0$ & $<0.00 I^{*}$ \\
\hline
\end{tabular}

Notes: *Statistically significant. "i", where seen as suffix, means parameter indexed to body surface area. $E^{0}$, transmitral early diastolic velocity; $E / A$, ratio of transmitral early to late diastolic velocity; TDe', early mitral annular septal tissue diastolic velocity; TDs', mitral annular septal tissue systolic velocity; E/e', ratio of transmitral early diastolic velocity to early mitral annular septal tissue diastolic velocity.

Abbreviations: PH, pulmonary hypertension; LAD, left atrial dimension; LVIDD, left ventricular internal dimension in diastole; EDV, end-diastolic volume; ESV, endsystolic volume; IVST, interventricular septal thickness; LVPWT, left ventricular posterior wall thickness; RVWT, right ventricular wall thickness; RVIDD, right ventricular internal diameter in diastole; LVM, left ventricular mass; RWT, relative wall thickness; LVEF, left ventricular ejection fraction; LVFS, left ventricular fractional shortening; SV, stroke volume; $\mathrm{Sl}$, stroke index; $\mathrm{CO}$, cardiac output; $\mathrm{Cl}$, cardiac index.

Table 6A lists the statistically significant correlates of the estimated MPAP. They include age $(r=0.467)$, hematocrit ( $r=-0.467), 6 \mathrm{MWD}(r=-0.571)$, left atrial dimension index $(r=0.397)$, and tissue Doppler systolic velocity $(r=$ $-0.387)$, all with a $p$ value $<0.001$. Other significant correlates are the ejection fraction $(r=-0.257 ; p=0.013)$, early mitral annular tissue diastolic velocity $e^{\prime}(r=-0.322 ; p=$ $0.002), E / e^{\prime}$ ratio and pulmonary capillary wedge pressure $(r=0.310 ; p=0.002)$, and right ventricular internal diastolic dimension index $(r=0.240 ; p=0.016)$. Table 6B lists the independent parameters linked to mean pulmonary artery pressure, which include hematocrit, age, left atrial dimension 
Table 5 (A) Significant correlates of TRV and (B) independent parameters linked to TRV

\begin{tabular}{|c|c|c|c|}
\hline \multicolumn{4}{|l|}{ A } \\
\hline Parameter & \multicolumn{2}{|c|}{ Pearson's correlation coefficient } & $p$ value \\
\hline Age (years) & \multicolumn{2}{|l|}{0.352} & 0.001 \\
\hline Hematocrit (\%) & \multicolumn{2}{|l|}{-0.326} & 0.001 \\
\hline 6MWD $(\mathrm{m})$ & \multicolumn{2}{|l|}{-0.442} & $<0.001$ \\
\hline LVEF (\%) & \multicolumn{2}{|l|}{-0.339} & 0.001 \\
\hline $\mathrm{TDe}^{\prime}(\mathrm{cm} / \mathrm{s})$ & \multicolumn{2}{|l|}{-0.279} & 0.007 \\
\hline $\mathrm{TDs}^{\prime}(\mathrm{cm} / \mathrm{s})$ & \multicolumn{2}{|l|}{-0.462} & $<0.001$ \\
\hline$E / e^{\prime}$ ratio & \multicolumn{2}{|l|}{0.270} & 0.009 \\
\hline LADi $\left(\mathrm{cm} / \mathrm{m}^{2}\right)$ & \multicolumn{2}{|l|}{0.290} & 0.005 \\
\hline LVIDDi $\left(\mathrm{cm} / \mathrm{m}^{2}\right)$ & \multicolumn{2}{|l|}{0.434} & $<0.001$ \\
\hline \multicolumn{4}{|l|}{ B } \\
\hline Parameter & $\begin{array}{l}\text { Unstandardized } \\
\text { coefficient }\end{array}$ & $\begin{array}{l}\text { Standardized } \\
\text { coefficient }\end{array}$ & $p$ value \\
\hline LADi $\left(\mathrm{cm} / \mathrm{m}^{2}\right)$ & -0.880 & -0.512 & $<0.001$ \\
\hline TDs $(\mathrm{cm} / \mathrm{s})$ & -0.193 & -0.428 & 0.002 \\
\hline Hematocrit (\%) & -0.040 & -0.203 & 0.021 \\
\hline Constant & 3.411 & & \\
\hline
\end{tabular}

Note: TDe', early mitral annular septal tissue diastolic velocity; TDs', mitral annular septal tissue systolic velocity; E/e', ratio of early transmitral diastolic flow velocity to early mitral annular septal tissue diastolic velocity.

Abbreviations: TRV, tricuspid regurgitant velocity; 6MWD, 6-minute walk distance; LVEF, left ventricular ejection fraction; LADi, left atrial dimension index LVIDDi, left ventricular internal diastolic dimension index; TDs, tissue Doppler systolic velocity.

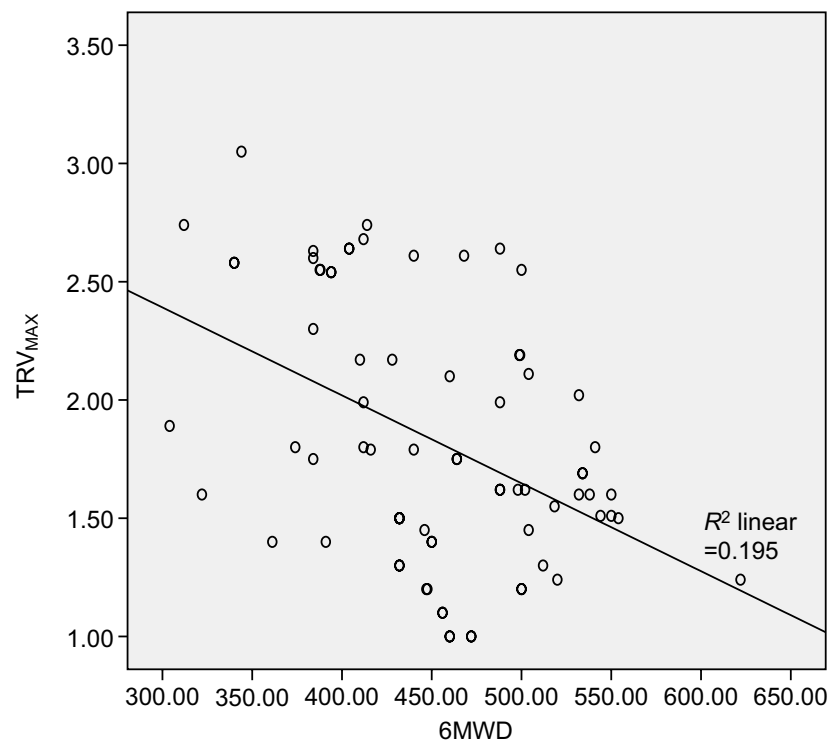

Figure I Correlation between $\mathrm{TRV}_{\max }$ and 6MWD.

Abbreviations: $\mathrm{TRV}_{\max }$, maximum tricuspid regurgitant velocity; 6MWD, 6-minute walk distance.

index, and 6MWD. Figure 2 shows a scatter plot depicting the correlation between MPAP and 6MWD. The higher the MPAP, the lower the distance walked in 6 minutes. Table 7 lists the independent parameters linked to $6 \mathrm{MWD}$, which include tissue Doppler systolic velocity, right ventricular diastolic dimension index, mean arterial pulmonary pressure, and hematocrit.
Table 6 (A) Significant correlates of estimated MPAP and (B) independent parameters linked to mean pulmonary arterial pressure

\begin{tabular}{|c|c|c|c|}
\hline \multicolumn{4}{|l|}{$\mathbf{A}$} \\
\hline Parameter & \multicolumn{2}{|c|}{ Pearson's correlation coefficient } & $p$ value \\
\hline Age (years) & \multicolumn{2}{|l|}{0.467} & $<0.001$ \\
\hline Hematocrit (\%) & \multicolumn{2}{|l|}{-0.467} & $<0.001$ \\
\hline 6MWD (m) & \multicolumn{2}{|l|}{-0.571} & $<0.001$ \\
\hline LADi $\left(\mathrm{cm} / \mathrm{m}^{2}\right)$ & \multicolumn{2}{|l|}{0.397} & $<0.001$ \\
\hline $\operatorname{LVEF}(\%)$ & \multicolumn{2}{|l|}{-0.257} & 0.013 \\
\hline $\mathrm{TDe}^{\prime}(\mathrm{cm} / \mathrm{s})$ & \multicolumn{2}{|l|}{-0.322} & 0.002 \\
\hline $\mathrm{TDs}^{\prime}(\mathrm{cm} / \mathrm{s})$ & \multicolumn{2}{|l|}{-0.387} & $<0.001$ \\
\hline E/e' ratio & \multicolumn{2}{|l|}{0.310} & 0.002 \\
\hline RVIDDi $\left(\mathrm{cm} / \mathrm{m}^{2}\right)$ & \multicolumn{2}{|l|}{0.249} & 0.016 \\
\hline \multicolumn{4}{|l|}{ B } \\
\hline Parameter & $\begin{array}{l}\text { Unstandardized } \\
\text { coefficient }\end{array}$ & $\begin{array}{l}\text { Standardized } \\
\text { coefficient }\end{array}$ & $p$ value \\
\hline Hematocrit (\%) & -1.105 & -0.270 & 0.003 \\
\hline Age (years) & 0.678 & 0.315 & 0.004 \\
\hline LADi $\left(\mathrm{cm} / \mathrm{m}^{2}\right)$ & 10.283 & 0.288 & 0.004 \\
\hline 6MWD $(\mathrm{m})$ & -0.041 & -0.231 & 0.038 \\
\hline Constant & 67.237 & & \\
\hline
\end{tabular}

Note: TDe', early mitral annular septal tissue diastolic velocity; TDs', mitral annular septal tissue systolic velocity; E/e', ratio of early transmitral diastolic flow velocity to early mitral annular septal tissue diastolic velocity.

Abbreviations: MPAP, mean pulmonary arterial pressure; 6MWD, 6-minute walk distance; LADi, left atrial dimension index; LVEF, left ventricular ejection fraction; RVIDDi, right ventricular internal diastolic diameter indexed to body surface area.

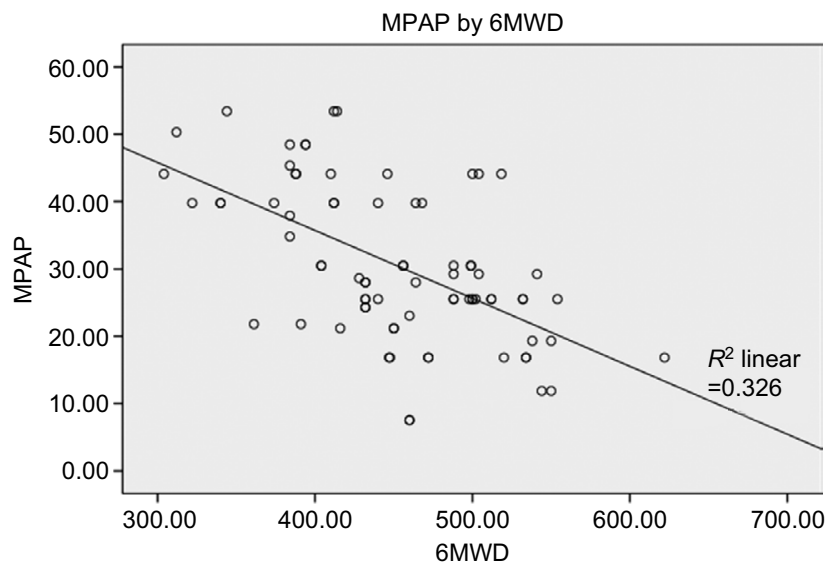

Figure 2 Correlation between MPAP and 6MWD.

Abbreviations: MPAP, mean pulmonary arterial pressure; 6MWD, 6-minute walk distance.

Table 7 Independent parameters linked to 6MWD

\begin{tabular}{llll}
\hline Parameter & $\begin{array}{l}\text { Unstandardized } \\
\text { coefficient }\end{array}$ & $\begin{array}{l}\text { Standardized } \\
\text { coefficient }\end{array}$ & p value \\
\hline TDs $(\mathrm{cm} / \mathrm{s})$ & 23.522 & 0.452 & 0.003 \\
RVIDDi $\left(\mathrm{cm} / \mathrm{m}^{2}\right)$ & -63.494 & -0.298 & 0.004 \\
MPAP $(\mathrm{mmHg})$ & -2.053 & -0.365 & 0.023 \\
Hematocrit $(\%)$ & 5.394 & 0.232 & 0.024 \\
Constant & 278.400 & & \\
\hline
\end{tabular}

Abbreviations: 6MWD, 6-minute walk distance; TDs, tissue Doppler systolic velocity; RVIDDi, right ventricular internal diastolic dimension index; MPAP, mean arterial pulmonary pressure. 


\section{Discussion}

This study showed that the overall prevalence of Dopplerderived PH in SCA was 38\%. This is similar to the results of the study by Oguanobi et al ${ }^{19}$ in Enugu (Southeastern Nigeria) who reported a prevalence of $41.9 \%$. The slightly lower, although comparable, values may be attributed to the fact that a more stringent criterion was used in the index study that included the AT/RVET ratio rather than an absolute cutoff point. This was to reduce the chances of over- or under inclusion of patients if a single cutoff point of $100 \mathrm{~ms}$ was used, given the wide variation in cutoff points of AT between 80 and $100 \mathrm{~ms}$ reported by different literature. ${ }^{17,18}$

When peak TRV was used, a total of 22 of the 92 (23.9\%) SCA patients had PH. These subjects equally met the second criterion used in the screening for $\mathrm{PH}$. The prevalence of $23.9 \%$ seen in this study is comparable to the findings of another study in Zaria (Northern Nigeria) by Aliyu et $\mathrm{al}^{20}$ who made use of peak TRV of $\geq 2.5 \mathrm{~m} / \mathrm{s}$ as a criterion and found a prevalence of $25 \%$. Dosunmu et $\mathrm{al}^{21}$ in a study in Lagos, Nigeria, got a much lower prevalence of 3.6\%. This low prevalence may be possibly due to the lower age group of the study sample compared to the present study. The resolution power of a machine used for the assessment of the tricuspid regurgitant jet may also be a contributory factor. However determined, the limitations of using the TRV were made up for. This is to suggest that echocardiographic assessment of pulmonary flow jet signal improves the yield in screening for $\mathrm{PH}$, given the limitations of the tricuspid regurgitation jet signal.

A significant relationship between Doppler-derived PH and exercise capacity was observed in this study. Those with PH had a significantly lower mean 6MWD during the self-paced walking exercise. Significant correlations were found between the indices of $\mathrm{PH}$ and exercise capacity. These findings corroborate those of previous research work done within and outside the country. ${ }^{20,22,23}$

Aliyu et $\mathrm{al}^{20}$ in Zaria studied 108 patients with SCA and observed that a higher tricuspid regurgitant jet velocity $>2.5 \mathrm{~m} / \mathrm{s}$ was associated with an inability to walk $>300 \mathrm{~m}$ in 6 minutes $(p=0.042)$.

Machado et a ${ }^{22}$ observed that $6 \mathrm{MWD}$ correlated inversely with tricuspid regurgitant jet velocity $(r=-0.62 ; p=0.0001)$ and mean pulmonary artery pressure $(r=-0.52 ; p=0.01)$, consistent with the 6MWD test reflecting the functional impairment in patients with $\mathrm{SCD}$ and $\mathrm{PH}$.

Anthi et al ${ }^{23}$ also observed that patients with SCA with PH exhibited lower 6MWD (320 $\pm 20 \mathrm{~m}$ vs $435 \pm 31 \mathrm{~m} ; p$ $=0.002)$ and oxygen consumption $(41 \pm 2 \%$ vs $50 \pm 3 \%$ of predicted; $p=0.02$ ) than control. They supported the use of 6MWD as an index of PH in patients with SCA.

The results obtained in this study showed that patients with SCA who had Doppler-derived PH were older, had lower hematocrit, and had lower 6MWD than those without $\mathrm{PH}$. The older age of the patients with SCA patients who had PH is probably not unconnected to the longer duration of exposure to the sequelae of chronic anemia, while the association with a lower PCV may be due to the effect of cell-free hemoglobin resulting from chronic hemolysis on nitric oxide bioavailability. ${ }^{78}$ Corroborating the findings of this study, Dosunmu et a ${ }^{21}$ also found a significant negative correlation between hematocrit (PCV) and estimated mean pulmonary artery pressure $(r=-0.3625 ; p=0.0425)$.

Echocardiographic assessment showed that patients with PH had lower ejection fraction and systolic tissue velocity but higher $E / e^{\prime}$ ratio and larger left atrial and right ventricular sizes than those without PH. Studies assessing the relationship of these parameters with pulmonary arterial pressure are sparse in the SCA population. However, a study by Hammoudi et $\mathrm{al}^{24}$ examined the relationship between cardiac structural changes and left ventricular diastolic dysfunction in SCA and observed that left atrial enlargement is common in SCA and was independently determined by age, hemoglobin concentration, and left ventricular end-diastolic volume index. Diastolic function as assessed by $E / e^{\prime}$ was not linked to left atrial size $(p=0.43)$. It was posited that left atrial enlargement may also be due to chronic volume overload.

The prevalence of $\mathrm{PH}$ in SCA derived by right heart catheterization ranges from $6 \%$ to $10 \% \cdot{ }^{5,25-27}$ In two separate studies by Parent et $\mathrm{al}^{26}$ in France and Fonseca et $\mathrm{al}^{27}$ in Brazil, the prevalence of $\mathrm{PH}$ as determined by right heart catheterization was $6.2 \%$ and $10 \%$, respectively. However, in these studies, the prerequisite for performing a right heart catheterization (an invasive procedure) was a TRV of $\geq 2.5 \mathrm{~m} / \mathrm{s}$.

Right heart catheterization is usually performed on SCA patients with a TRV of $\geq 2.5 \mathrm{~m} / \mathrm{s}$ with or without an $\mathrm{N}$-terminal pro-brain natriuretic peptide (NT-proBNP) $\geq 160 \mathrm{pg} / \mathrm{mL} .{ }^{5}$ NT-proBNP, which is a marker for left or right ventricular strain, becomes useful when Doppler echocardiography is unavailable or when there are difficulties with image acquisition. ${ }^{5}$

Fonseca et $\mathrm{al}^{27}$ reported a trend for worse survival in patients with a TRV of $\geq 2.5 \mathrm{~m} / \mathrm{s}$ compared with those who have a TRV of $<2.5 \mathrm{~m} / \mathrm{s}$

In adults with SCD, an increased TRV $>2.5 \mathrm{~m} / \mathrm{s}$ measured by Doppler echocardiography, an increased serum NT- 
proBNP level $>160 \mathrm{pg} / \mathrm{mL}$, and PH diagnosed by right heart catheterization are independent risk factors for mortality. ${ }^{2,5,14}$

Recent American Thoracic Society (ATS) guidelines state that patients identified at high risk of death should be screened for comorbid factors that are treatable, including low oxygen tension, iron overload, and thromboembolic disease. ${ }^{5}$ The underlying SCD should be treated more aggressively with hydroxyurea therapy or chronic exchange blood transfusion therapy. Patients diagnosed to have PAH should be referred to PAH specialists for Food and Drug Administration-approved PAH therapies. ${ }^{5,8}$

Before any specific treatment for $\mathrm{PH}$ is considered, there is need for invasive hemodynamics. Both pre- and post-capillary hemodynamic profiles are found in SCA, stressing the need for a better understanding of the multiple pathophysiological mechanisms involved in the development of $\mathrm{PH}$ before considering the patients for targeted therapies. ${ }^{28}$

\section{Conclusion}

Doppler-derived PH is a common finding in Nigerian adults with SCA, seen in $23.9 \%$ of patients using TRV and $38 \%$ of patients using pulmonary flow Doppler. It significantly affects exercise capacity negatively, and has significant relationships with some clinical parameters and echocardiographic indices of cardiac structure and function. Thus, screening for $\mathrm{PH}$ is to be encouraged if the quality of life and life expectancy of this group of patients are to be improved upon.

\section{Acknowledgments}

The significant contributions of Prof AO Fatusi, who was, at the time the study was conducted, the head of the Institute of Public Health of Obafemi Awolowo University, Ile-Ife, Nigeria, in offering statistical advice are very much appreciated. This work was carried out in the Cardiac Care Unit and Department of Haematology and Blood Transfusion of the OAUTHC, Ile-Ife, Osun State, Nigeria. This work was supported by the management of OAUTHC, Ile-Ife, Osun State, Nigeria.

\section{Disclosure}

The authors report no conflicts of interest in this work.

\section{References}

1. Platt OS, Brambilla DJ, Rosse WF, et al. Mortality in sickle cell disease. Life expectancy and risk factors for early death. $N$ Engl J Med. 1994;330(23):1639-1644.

2. Gladwin MT, Sachdev V, Jison ML, et al. Pulmonary hypertension as a risk factor for death in patients with sickle cell disease. $N$ Engl J Med. 2004;350(9):886-895.
3. Castro O, Hoque M, Brown BD. Pulmonary hypertension in sickle cell disease. Cardiac catheterization results and survival. Blood. 2003; 101(4):1257-1261.

4. Hoepner MM, Bogaar HJ, Condliffe R, et al. Definitions and diagnosis of pulmonary hypertension. J Am Coll Cardiol. 2013;62(25):D42-D50.

5. Hayes MM, Vedamurthy A, George G, et al. Pulmonary hypertension in sickle cell disease. Ann Am Thorac Soc. 2014;11(9):1488-1489.

6. Hughes JM, Morrell NW. Pulmonary Circulation: From Basic Mechanisms to Clinical Practice. London: Imperial College Press; 2001.

7. Reiter CD, Wang X, Tanus-Santos JE, et al. Cell-free hemoglobin limits nitric oxide bioavailability in sickle-cell disease. Nat Med. 2002; 8(12):1383-1389

8. Potoka KP, Gladwin MT. Vasculopathy and pulmonary hypertension in sickle cell disease. Am J Physiol Lung Cell Mol Physiol. 2015; 308(4):L314-L324.

9. McLaughlin VV, Richard C. Sickle cell disease-associated pulmonary hypertension; a coat of many colors. Am J Respir Crit Care Med. 2007; 175(12):1218-1219.

10. Simonneau G, Gatzoulis MA, Adatia I, et al. Updated clinical classification of pulmonary hypertension. J Am Coll Cardiol. 2013; 62(25):D34-D41.

11. Klings ES, Morris CR, Hsu LL, Castro O, Gladwin MT, Mubarak KK. Pulmonary hypertension of sickle cell disease beyond classification constraints. J Am Coll Cardiol. 2014;63(25):2881-2882.

12. Souza R, Simonneau GJ. Reply: pulmonary hypertension of sickle cell disease beyond classification constraints. J Am Coll Cardiol. 2014; 63(25_PA):2882-2883.

13. Badesch DB, Champion HC, Sanchez MA, et al. Diagnosis and assessment of pulmonary arterial hypertension. J Am Coll Cardiol. 2009; 54(1 suppl):S55-S56.

14. Klings ES, Machado RF, Barst RJ, et al. An official American Thoracic Society Clinical Practice Guideline: diagnosis, risk stratification and management of pulmonary hypertension of sickle cell disease. Am J Respir Crit Care Med. 2014;189(6):727-740.

15. Akinola NO, Stevens SM, Franklin IM, Nash GB, Stuart J. Subclinical ischaemic episodes during the steady state of sickle cell anaemia. J Clin Pathol. 1992;45(10):902-906.

16. Lang RM, Bierig M, Devereux RB, et al. Recommendations for chamber quantification: a report from the American Society of Echocardiography's Guidelines and Standards Committee and the Chamber Quantification Writing Group, developed in conjunction with the European Association of Echocardiography, a branch of the European Society of Cardiology. J Am Soc Echocardiogr. 2005;18(12):1440-1463.

17. Kitabatake A, Inoue M, Asao M, et al. Noninvasive evaluation of pulmonary hypertension by a pulsed Doppler technique. Circulation. 1983; 68(2):302-309.

18. Dabestani A, Mahan G, Gardin JM, et al. Evaluation of pulmonary artery pressure and resistance by pulsed Doppler echocardiography. Am J Cardiol. 1987;59(6):662-668.

19. Oguanobi NI, Ejim EC, Anisiuba BC, et al. Clinical and electrocardiographic evaluation of SCA patients with pulmonary hypertension. ISRN Haematol. 2012;2012:768718.

20. Aliyu ZY, Gordeuk V, Sachdev V, et al. Prevalence and risk factors for pulmonary artery systolic hypertension among sickle cell disease patients in Nigeria. Am J Hematol. 2008;83(6):485-490.

21. Dosunmu AO, Balogun TM, Adeyeye OO, et al. Prevalence of pulmonary hypertension in Sickle cell anaemia patients of a tertiary hospital in Nigeria. Niger Med J. 2014;55(2):161-165.

22. Machado RF, Martyr S, Kato GJ, et al. Sildenafil therapy in patients with sickle cell disease and pulmonary hypertension. Br J Hematol. 2005;130(3):445-453.

23. Anthi A, Machado RF, Jison ML, et al. Hemodynamic and functional assessment of patients with sickle cell disease and pulmonary hypertension. Am J Respir Crit Care Med. 2007;175(12):1272-1279.

24. Hammoudi N, Charbonnier M, Levy P, et al. Left atrial volume is not an index of left ventricular diastolic dysfunction in patients with sickle cell anaemia. Arch Cardiovasc Dis. 2015;108(3):156-162. 
25. Simonneau G, Parent F. Pulmonary hypertension in patients with sickle cell disease: not so frequent but so different. Eur Respir J. 2012; 39(1):3-4.

26. Parent F, Bachir D, Inamo J, et al. A haemodynamic study of pulmonary hypertension in sickle cell disease. $N$ Eng J Med. 2011;365(1):44-53.
27. Fonseca GHH, Souza R, Salemi VMC, Jardim CVP, Gualandro SFM. Pulmonary hypertension diagnosed by right heart catheterization in sickle cell disease. Eur Respir J. 2012;39(1):112-118.

28. Fonseca GHH, Souza R. Pulmonary hypertension in sickle cell disease. Curr Opin Pulm Med. 2015;21(5):432-437.

\section{Publish your work in this journal}

Vascular Health and Risk Management is an international, peerreviewed journal of therapeutics and risk management, focusing on concise rapid reporting of clinical studies on the processes involved in the maintenance of vascular health; the monitoring, prevention and treatment of vascular disease and its sequelae; and the involvement of metabolic disorders, particularly diabetes. This journal is indexed on PubMed Central and MedLine. The manuscript management system is completely online and includes a very quick and fair peer-review system, which is all easy to use. Visit http://www.dovepress.com/ testimonials.php to read real quotes from published authors. 